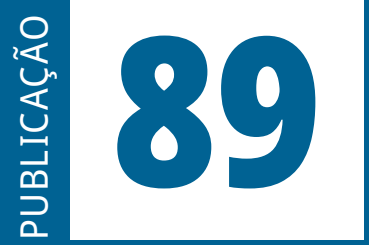

ISSN: 0101-9562

ISSN ELETRÔNICO: 2177-7055

SEQÜÊNCIA

Publicação do

Estudos jurídicos

e políticos

Programa de Pós-Graduação em Direito da UFSC

VOLUME 42 - ANO 2021 
SEQUÊNCIA - ESTUDOS JURÍDICOS E POLÍTICOS é uma publicação temática e de periodicidade quadrimestral, editada pelo Programa de Pós-Graduação Stricto Sensu em Direito da Universidade Federal de Santa Catarina - UFSC.

SEQUÊNCIA - ESTUDOS JURÍDICOS E POLÍTICOS is a thematic publication, printed every four months, edited by the Program in law of the Federal University of Santa Catarina - UFSC.

Versão eletrônica: http://www.periodicos.ufsc.br/index.php/sequencia

A publicação é indexada nas seguintes bases de dados e diretórios/

The Publication is indexed in the following databases and directories:

Base OJS

Base PKP

CCN (Catálogo Coletivo Nacional)

Dialnet

DOAJ (Directory of Open Access Journals)

EBSCOhost

Genamics Journalseek

ICAP (Indexação Compartilhada de Artigos de Periódicos)

Latindex

LivRe!

OJS
PKP
Portal de Periódicos UFSC
Portal do SEER
ProQuest
SciELO
Sherpa/Romeo
Sumarios.org
ULRICH'S
vLex

Ficha catalográfica

Seqüência: Estudos jurídicos e políticos. Universidade Federal de Santa Catarina.

Programa de Pós-Graduação em Direito. n.1 (janeiro 1980)-.

Florianópolis: Fundação José Boiteux. 1980-.

Publicação contínua

Resumo em português e inglês

Versão impressa ISSN 0101-9562

Versão on-line ISSN 2177-7055

1. Ciência jurídica. 2. Teoria política. 3. Filosoia do direito. 4. Periódicos.

I. Universidade Federal de Santa Catarina. Programa de Pós-graduação em

Direito

CDU 34(05)

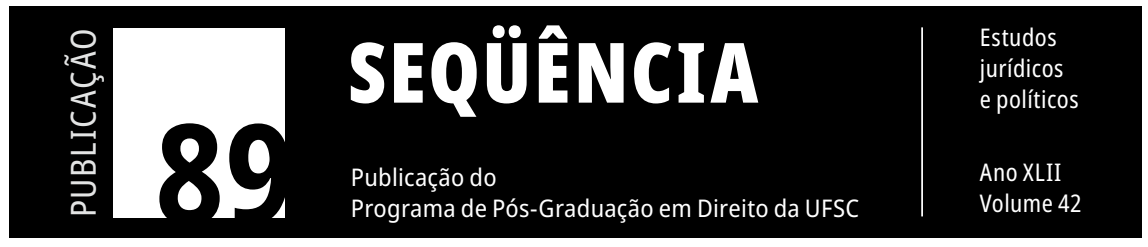




\title{
A gestão de ilegalismos de Foucault como categoria de análise de questões jurídicas no Brasil
}

\section{The tool "illegalisms" by Foucault as a category of analysis for legal problems in Brazil}

\author{
Gretha Leite Maia ${ }^{1}$ \\ ${ }^{1}$ Universidade Federal do Ceará, Fortaleza, Brasil \\ David Barbosa Oliveira ${ }^{2}$ \\ ${ }^{2}$ Universidade Federal do Ceará, Fortaleza, Brasil
}

RESUMO: A proposta desse artigo é examinar e fornecer um subsídio teórico e analítico para pesquisas jurídicas. Para tanto, empreendeu-se uma pesquisa exploratória que investigou a ferramenta "ilegalismo" e suas possíveis contribuições como categoria de análise para definir e explicar problemas normativos e a atuação do judiciário na modernidade. O principal referencial é Foucault, cuja leitura foi feita de par com as contribuições de Delleuze sobre Foucault. Foram feitos também aportes significativos das leituras de Rusche e Kirchheimer sobre o debate. Examinada essa possibilidade, restará estabelecida uma categoria de análise válida para estudos da atuação do judiciário brasileiro. Trata-se, por fim, de pesquisa bibliográfica, exploratória, de caráter teórico e analítico.

PALAVRAS-Chave: Ilegalismos - Judiciário - Direito.

ABSTRACT: The purpose of this article is to examine and provide a theoretical and analytical support for legal research. To this end, an exploratory research was carried out that investigated the tool "illegalisms" and its possible contributions as a category of analysis to define and explain the normative problems and the performance of the judiciary in modern times. The main reference is Foucault, whose reading was done in parallel with Delleuze's contributions on Foucault. Significant contributions were also made from the readings of Rusche and Kirchheimer on the debate. After examining this possibility, a valid analysis category 
will be established for studies on the performance of the Brazilian judiciary. Finally, it is a bibliographic, exploratory, theoretical and analytical research.

KEYWORDS: Illegalisms - Judiciary - Law.

\section{INTRODUÇÃO}

A pesquisa que embasa o presente artigo tem como um de seus fundamentos a afirmação de que é preciso estabelecer categorias de análise para a realização de estudos que possam contribuir para a compreensão de questões relativas às tensões na delimitação e instrumentalização do limite entre legalidade e ilegalidade, uma vez que tais tensionamentos traduzem as práticas do judiciário. Trata-se, portanto, de pesquisa bibliográfica, exploratória, de caráter teórico e analítico.

O objetivo desse trabalho é investigar a possibilidade de contribuição do conceito de gestão de ilegalismos para definir a atuação do judiciário na modernidade, levando em conta a existência de um específico sistema de normas. Investiga também sua aplicabilidade nos estudos que analisam a atuação do judiciário brasileiro, seja do ponto de vista da análise histórica, seja da atuação contemporânea. $\mathrm{O}$ principal referencial é a teoria dos ilegalismos de Foucault, cuja leitura foi feita de par com as principais contribuições de Delleuze. Também se estabeleceu um diálogo da obra de Rusche e Kirchheimer como uma referência do próprio Foucault.

A pesquisa parte da constatação de que houve um longo processo de formalização da Lei, especialmente ligada a uma política de punição, como garantia da posição social e econômica para a burguesia, que perpassou os séculos XVII, XVIII e XIX na Europa. Para apoiar tal constatação, foram examinadas as contribuições especialmente de Thompson e Darnton, com a indicação de episódios culturais que ilustram esse processo no cenário europeu. Compreende-se que esse processo de formalização da Lei, da codificação do direito penal à legislação trabalhista, e da afirmação do papel do Judiciário na gestão 
da ilegalidade, enquanto processo, se encontra em permanente construção e é instável por definição.

O trabalho investiga, portanto, a aptidão das categorias de análise propostas por Foucault quando aplicadas na construção de um discurso explicativo não apenas sobre as formas jurídicas, mas também sobre dinâmicas jurisdicionais no Brasil, podendo ser aplicado em estudos do judiciário brasileiro, de viés historiográfico, e estudos sobre as dinâmicas do judiciário contemporâneo.

\section{ENTRE A PLEBE SEDICIOSA E A BURGUESIA REVOLUCIONÁRIA: A GESTÃO DE ILEGALISMOS}

Foucault, no curso do Collège de France, entre 1972 e 1973, é provocado pelas teorias de Lévi-Strauss sobre as soluções que certas sociedades encontraram para dar conta do indivíduo perigoso e dotado de força temível e hostil, identificando-as como: antropofágicas quando assimilavam e neutralizavam esta força ou antropoemias, quando decidiam pela expulsão dos portadores dessas forças do corpo social. Foucault parte desta análise de Lévi-Strauss, mas entende que essa explicação é muito ampla e dicotômica, no que sugere outra solução, a saber: as "táticas finas de sanção" (Foucault, 2015, p. 7). Entre a genealogia da prisão e sua função na sociedade, Foucault então apresenta o que ele chamará de teoria dos ilegalismos. Para compreender a teoria, foi preciso resgatar alguns de seus pressupostos.

$\mathrm{O}$ argumento de Foucault de que, com o crescimento do capitalismo, correspondeu toda uma série de movimentos de sedição popular, aos quais a burguesia respondeu com um novo sistema judiciário e penitenciário, parte dos estudos feitos por Thompson (1987a e 1987b). Para Fortes (1995), Thompson compreende o direito como um espaço de conflito que repercute diretamente na restituição a setores submetidos ao longo da história às mais variadas formas de dominação à plenitude da condição de sujeitos. Deste modo, o conflito se 
estabelece no fato de haver uma tensão entre as forças que dominam e as que buscam equiparação.

Para Thompson, em todas as épocas, há um código popular que se afirma ao lado de um código legal. A legitimação popular e a repressão estatal ante a sedição popular, na segunda metade do século 18, por exemplo, se enquadram dentro desse conflito. É comum, de acordo com Thompson (1987a), que, no código popular, certos crimes sejam tolerados como, por exemplo, o não pagamento de taxas, a cunhagem de moedas falsas ou a fuga do recrutamento. Outros, contudo, eram punidos pela própria população, como atentar contra a subsistência de uma comunidade ou o assassinato de crianças e mulheres. Não há, por conseguinte, um prévio salvo conduto ante as ilegalidades populares.

A par desse conflito, ainda em torno do Direito, havia o debate sobre o "consenso moral" que as autoridades inglesas impunham sobre a sociedade ao estabelecer "limites além dos quais não se poderia 'empurrar' o inglês", limites que as autoridades não ousariam transpor no controle da sociedade (ThOMPSON, 1987a, p. 86). Era um código que formatava as possibilidades de conduta dentro do que se entendia como lícito e moralmente aceito. Às tentativas de compor, por exemplo, um júri faccioso, de suspensão do habeas corpus ou de construção de um sistema continental de espionagem, eram consideradas como agressões a esse "consenso moral" e eram freadas por protestos populares. Dentro do corpo legal, não havia punições para as ações arbitrárias das autoridades que interviessem a força sobre os direitos pessoais ou de propriedade, ao passo que havia uma legislação dura quando as camadas populares agrediam a propriedade. Contudo, essa legislação rígida era contrabalanceado, pela aplicação liberal dos juízes e pelo júri que, em alguns casos, oferecia importante proteção. Existia, assim ao lado de um código penal "sanguinário" (Thompson, 1987a), uma interpretação e uma aplicação liberal das leis.

Darnton (2015) ocupa-se também de desvelar, por meio de episódios da cena cultural dos séculos XVII e XVIII, essa sutil relação 
entre a revolta popular legítima, espontânea e acolhida, e a necessidade de controle das insurreições da turba. Destacando episódio como o grande massacre dos gatos da rua Saint-Severin, em 1730, Darnton demonstra como podiam ser as revoltas dos trabalhadores por meio de sedições que irrompiam no cotidiano das oficinas e que representavam as respostas difusas às injustiças nas relações empregados e empregadores. O massacre é protagonizado inicialmente por dois aprendizes de uma gráfica, que viviam em duras condições, executando tarefas o dia inteiro. A faina transcorria entre insultos dos oficiais (assalariados) e aos maus-tratos dos patrões (mestres), sem nada receber para comer a não ser sobras. Como a mulher do patrão adorava gatos, "os aprendizes resolveram endireitar esse estado de coisas desigual" (DARnTON, 2015, p.106). Por meio de uma artimanha, convenceram os patrões a autorizar uma caça aos inúmeros gatos de rua, excluídos os da casa e, reunindo certa quantidade de gatos, a essa altura já semimortos, entre os da rua e os de casa, fingiram um julgamento e os gatos foram considerados culpados. A cena se encerra com o delírio dos trabalhadores, entre a alegria e a desordem. A revolta indicava a consciência difusa de que o trabalho se tornara cada vez mais uma mercadoria e menos uma relação de parceira. $\mathrm{O}$ trabalhador sofre com as intermitências de demanda de trabalho, numa sequência de demissões e novas contratações, que por vezes torna-se um longo e penoso intervalo. Há registro de inúmeros tribunais populares improvisados, num jogo simbólico de compensação.

Havia, assim, uma espécie de lutas de classes entre a força estatal, de um lado, e o crime, a turba e o distúrbio de outro. As ações turbulentas eram legitimadas, na Inglaterra, pelo entendimento de que a Revolução Gloriosa proporcionava um precedente constitucional para o direito de motim como maneira de resistência à repressão. Para Thompson (1987a, p. 86), o constitucionalismo era a "ilusão da época". Assim, a tensão entre a plebe sediciosa e a repressão ou tolerância do Estado permanece até a revolução francesa em uma disputa que estabeleciam dominações provisórias e resistências contingentes. Esta 
licenciosidade apenas se esgota na década de 1790, segundo Fortes (1995), com o temor causado pela agitação jacobina na Inglaterra e sua associação com o processo revolucionário francês, gerando uma quebra de reciprocidade.

$\mathrm{Na}$ França, “às vésperas do Leviathan”, fosse no campo das relações de produção, fosse no campo das infrações ditas criminais, havia de fato uma disputa pelo poder de controlar as condutas e punir os desvios de conduta. O Estado disputava ombro a ombro com a Igreja, com as corporações de ofício e guildas comerciais, o controle do comportamento, havendo ainda conflitos cuja solução era reivindicada pela plebe, pelos trabalhadores e pelos próprios desviantes. Enquanto Darnton explora momentos em que "ser ilegal" foi o trunfo apontado como heroico de uma resistência a tiranias, Foucault se refere a esse fenômeno como a sedição popular.

Para Foucault, o mecanismo que trouxe a formação desse sistema punitivo é mais profundo e mais amplo do que o simples controle da plebe. Para Foucault (2001),

En fait, je ne crois pas que ce soit tellement le problème de la plèbe séditieuse qui est essentiel, c'est le fait que la fortune bourgeoise s'est trouvée, par les nécessités même du développement économique, investie de telle manière qu'elle était entre les mains de ceux-là mêmes qui étaient chargés de produire. Tout travailleur était un prédateur possible. Et toute création de plus-value était en même temps l'occasion, ou en tout cas la possibilité, d'une soustraction éventuelle.

Assim, a sedição popular, para Foucault, é um caso particular de um fenômeno mais constante: o ilegalismo popular. Antes de continuarmos é importante deixar evidente que ilegalismo é um neologismo de Foucault. Ilegalismo (illégalisme), cujo sentido, como explica Souto (2010), contrasta com o conceito jurídico de ilegalidade e alude às práticas a favor e contrárias a ela. Assim, segundo Foucault, "certo ilegalismo popular era não só compatível com o desenvolvimento da economia burguesa, como também útil a ele" (2015, p. 130). Mas não 
havia, na visão de Foucault, apenas o ilegalismo popular. A produção capitalista assimilou certas ilegalidades comerciais em seu momento embrionário que fomentaram a expansão industrial, pois era uma forma de se esquivar das cobranças feudais. Havia ainda o ilegalismo dos privilegiados que escapavam da lei por estatuto, tolerância ou exceção.

Havia, assim, a competição de quatro ilegalismos: o popular, o comercial, o privilegiado e o do poder que fazia o sistema funcionar. De acordo com Foucault, "entre a ilegalidade de baixo e as das outras castas sociais, não havia exatamente convergência, nem oposição fundamental” (1987, p. 71). Esses ilegalismos permeavam a sociedade inteira e se colocavam não contra a propriedade, mas contra os direitos feudais, ou uma específica concepção de propriedade feudal. Conforme Grossi (2006), o conceito de propriedade medieval é distinto do conceito de propriedade moderna, sobretudo no caso da propriedade de terras. A Revolução Francesa é que consolida essa noção burguesa de propriedade, abolindo privilégios (da nobreza) e cancelando direitos perpétuos. A sociedade moderna assim, para Grossi (2006), é uma sociedade proprietária, tendo no código civil napoleônico o lócus de definição do que seria o direito de propriedade: "la propriété est le droit de jouir et disposer des choses de la manière plus absolue". Tanto o Código Francês de 1810 quanto o Código Italiano de 1865 definem assa noção moderna de propriedade como o direito de gozar e dispor do bem de modo absoluto. Tal definição descolava de forma irreversível os camponeses de seu lugar de sobrevivência, promovendo uma revolução no modo de vida do trabalhador agrário, gerando deslocamentos, desterritorialização e desorientação para pelo menos uma geração de camponeses.

Ante as inúmeras mudanças que se sucediam na sociedade, dentro de um intenso período de transição, com o abandono de certas formas jurídicas para a instalação de outras, a tolerância às ilegalidades, ou seja, a gestão dos ilegalismos era uma economia de poder através do Direito. Os diferentes estratos destarte tinham, segundo Foucault, uma margem de ilegalidade tolerada e a não 
aplicação de determinada regra ou a inobservância de inúmeros editos ou ordenações eram condição do funcionamento político e econômico da sociedade. Os intendentes, subdelegados e tenentes de polícia eram, nesse contexto, mais que agentes da arbitrariedade, eram árbitros dos ilegalismos.

O poder gerenciava os ilegalismos, que atuavam uns contra os outros, e intervinha, não raras vezes, para diminuir as penalidades. A burguesia tinha diante desse estado de coisas uma posição ambígua: apoiava as lutas quando lhe serviam, como no uso da multidão pelos “wilkistas", (Тномром , 1987a, p. 74) e dava-lhe as costas quando caiam na criminalidade comum ou quando assumiam a forma de lutas políticas, como no caso do "tribunal do pão" ou no "grande motim do queijo", (Тномрsom, 1987a, p. 66 e 67), bem como nos distúrbios ligados ao luddismo em Yorkshire e em Nottingham (Тномрsом, 1987 b, p. 125). O ilegalismo popular também possuía uma postura oscilante, não havia uma tomada de posição definitiva de se situar contra a lei, permanecendo num jogo com os demais ilegalismos.

Para Foucault (2015), a burguesia, apoiando-se ora num ilegalismo popular (utilizando como sua vanguarda de combate), ora num ilegalismo dos privilegiados (tentando acessar algum privilégio), findou por desequilibrar as formas jurídicas e possibilitar a apropriação do aparato judiciário, coibindo o ilegalismos popular que ficara pesado demais para ela, já que os estratos populares tiveram que passar das fraudes ao roubo.

O ilegalismo que atuava inclusive desenvolvendo a economia tornou-se, entretanto, incompatível com ele. Com o crescimento do poder nas mãos da burguesia, houve, portanto, uma nova composição da gestão dos ilegalismos, reivindicando a burguesia o privilégio exclusivo de evitar a lei, controlando não só sua aplicação, mas também sua elaboração. A partir de então o ilegalismo dos bens foi separado do ilegalismo dos direitos. Para Foucault (1987), o ilegalismo popular que se detém sobre os bens passa a não ser mais admitido, sendo coibidas pelos tribunais e o ilegalismo dos direitos corre a margem da lei, num 
campo de informalidade que será, em caso de conflito, resolvido em jurisdições especiais com transações, acomodações e multas atenuadas.

\section{APORTES PARA AS INTUIÇÕES FOUCAULTIANAS}

Para desvelar as diversas camadas do pensamento intuitivo de M. Foucault, abre-se agora um diálogo com uma contribuição que lhe antecede. $\mathrm{O}$ argumento do uso da lei para controle social por razões econômicas e não humanitárias, como se quis ao embalo do pensamento filosófico e político do século XVIII, é defendido por Rusche e Kirchheimer em uma ampla pesquisa, publicada pela primeira vez em 1939, que leva em conta a instalação e as transformações do capitalismo a partir do século XVI.

Ao analisarem o mercantilismo e sua específica relação com o surgimento da prisão, os pesquisadores afirmam que os métodos de punição começam a sofrer uma mudança gradual e profunda em fins do século XVI. Amplia-se a exploração do trabalho de prisioneiros e penas como a escravidão nas galés, deportação e servidão penal por meio de trabalhos forçados são os produtos de "certo desenvolvimento econômico que revelava o valor potencial de uma massa de material humano completamente à disposição das autoridades" (RusCHE E KIRCHHEIMER, p.43). Os pesquisadores apontam uma grande instabilidade na relação entre crescimento demográfico (quantidade e distribuição da força de trabalho) e salário, preço dos bens de vida e condições de trabalho nesses anos de formação do sistema econômico capitalista.

Eles concluem que, por considerar a acumulação do capital como necessária para a expansão dos negócios, “os capitalistas foram obrigados a apelar ao Estado para garantira redução dos salários e a produtividade do capital" (Rusche E KirchHeimer, p.47). Essa estratégia é apontada pelos pesquisadores nas formas de controle social protagonizadas no interesse do sistema econômico, que abrangiam o controle ou estímulo da natalidade, uma das grandes preocupações dos 
economistas do século XVIII: o rei precisava de súditos, os exércitos de soldados, os empregadores de trabalhadores. O controle dessa massa humana estava em disputa, mas era incontroversa sua necessidade, e esse controle está no centro da ideologia dos grandes Códigos legais do século XIX.

Quando se tornava difícil encontrar soldados ou trabalhadores, sobretudo pelo aumento do valor exigido por estes pela jornada, "juízes e carcereiros eram consultados sobre adequação dos condenados para o serviço militar, e o critério de classificação era o físico, e não moral" (Rusche E Kirchheimer, p.51). O exército foi considerado um tipo de organização penal apropriado para errantes, extravagantes e ex-condenados. A política do período mercantilista revela um mercado muito favorável aos empregadores, uma vez que o florescimento da indústria também era do interesse das forças políticas, no arco que vai do absolutismo ao Estado nação. Os Estados disputavam, garantiam e incentivavam um modelo produtivo por meio de privilégios e monopólios e a indústria têxtil era especialmente visada: os estados garantiam das instalações aos trabalhadores. $\mathrm{O}$ crescimento econômico continuado desse modelo demandava a criação de uma grande reserva de força de trabalho. Os pesquisadores qualificam como natural que Estado (também ele um empregador) e empregadores privados (os donos do capital acumulado) convergissem no interesse na existência de uma força de trabalho a baixo custo. O grande esforço da regulamentação estatal do mercado de trabalho foi, sobretudo, na proibição da organização da classe trabalhadora.

Todo esse cenário é restaurado para se entender o tratamento da riqueza e da pobreza. Tomando por exemplo o tratamento dado ao trabalho infantil, tem-se que a ausência de qualquer regulamentação fazia com que uma criança fosse posta na fábrica tão logo pudesse, o que se traduzia em uma ausência de alfabetização endêmica na classe trabalhadora. Durante séculos, cuidar da pobreza era tarefa da Igreja. Aos poucos o Estado passa a assumir essa tarefa, de par com a organização dos processos produtivos: as primeiras escolas de massa eram 
industriais. Deve ser lembrado, entretanto, que jamais foi abandonada a estratégia do uso da religião como um meio de inculcar a disciplina e a disposição para o trabalho pesado. De um lado, para os vagabundos e vadios que escapavam do processo disciplinador, a pena; antes dela, um complexo sistema de controle de comportamento da classe trabalhadora, desde um processo educacional até a compreensão de que o trabalho, sob quaisquer condições, é aquilo que dignifica o homem. As motivações econômicas foram a força motriz desse movimento.

Foram propostas diferenciações nas penas considerando as várias categorias de transgressores. No caso das colônias, a deportação foi uma pena que concorreu com a escravização de africanos como oferta de mão-de-obra cativa. Vadios, mendigos e desocupados deveriam ir para as "casas de trabalho" enquanto delinquentes graves (assassinos e ladrões) iam para as "casas de correção". O objetivo das primeiras era a exploração racional e barata da força de trabalho. O "aprisionamento" é incrementado com o reconhecimento da necessidade de tratamento diferenciado para mulheres e membros de determinados estratos sociais: o encarceramento em hospitais ou "casas de repouso".

A gestão dos ilegalismos, portanto, corresponde à ideologia política e econômica do Estado moderno. Do ponto de vista filosófico, sua elaboração e promoção foram tarefas do Iluminismo. Daí emerge a formulação legal da culpa, não mais apenas um problema ético ou moral. A pena, como consequência do delito, passa a ser um dado juridicamente definido: "a paixão da época por matemática, combinada com o desejo burguês por segurança, levou a uma identificação da justiça como um cálculo" (Rusche e Kirchheimer, p.111). Tal é o fundamento do grande esforço concentrado em desenvolver um elaborado sistema de legislação que reconhecesse todas as distinções entre os crimes, consagrando a afirmação de que, se a privação da liberdade é considerada o resultado natural para a ofensa à propriedade, a propriedade e a liberdade pessoal têm valor igual.

De par com as preocupações de estabelecimento do controle social pela via da legalidade, houve um movimento contra o que eram 
consideradas deficiências dos procedimentos legais e judiciais. Se, de acordo com Rusche e Kirshheimer (2013, p.118), demandas como julgamentos públicos, livre escolha de um advogado, proteção contra o encarceramento ilegal, supressão da tortura e normas definidas para o procedimento probatório, foram feitas em nome da humanidade e do progresso humano, "a experiência mostrou que os efeitos dos novos procedimentos diferiam bastante entre as classes, a despeito de uma certa tendência para o crescimento das garantias gerais". Como consequência, não só se deixavam de apenar membros da burguesia e da aristocracia, como se incentivava comportamentos fora da lei.

Tornou-se uma questão clara de classe o controle da administração da justiça, uma vez que se consolidava a noção de poder de criação do direito pelos juízes, a despeito do movimento legalista. Uma coisa era a proposta de um sistema formal e racional de leis penais, outra bem diferente era a administração da justiça criminal. Os magistrados foram aos poucos se tornando os agentes mais efetivos do sistema de repressão. Os pesquisadores ressaltam a coincidência do discurso dos princípios humanitários, que contrastavam com medidas que evidenciavam a prioridade de satisfação das necessidades de um modelo econômico, como o uso abusivo de leis contra a vadiagem.

O fim da "política social mercantilista" é determinado pela estabilização demográfica do mercado de trabalho que, com a revolução industrial, em pouco tempo estaria saturado, levando a classe trabalhadora a mais um período de empobrecimento e miséria. Dessa classe empobrecida surge o proletariado moderno e o exército industrial de reserva. Volta-se para o Estado a demanda do que fazer com o problema da pobreza. Rusche e Kirshheimer (2013) afirmam que as mudanças nas condições sociais transformaram o trabalho, que fora ensinado às massas como sendo sua obrigação e então se torna um direito. Note-se que até hoje a questão do direito ao trabalho permanece como uma reivindicação política da classe trabalhadora (o que lhe dá até mesmo a identidade), uma vez que a ideia disseminada de que "todo homem predisposto ao trabalho pode achar emprego" 
deixou de ser crença comum. Por outro lado, dados trazidos pelos pesquisadores apontam um crescimento notável dos delitos contra a propriedade em fins do século XVIII e começo do XIX. As penas mais duras não eram suficientes, contrariando as propostas utilitaristas da punição. De toda forma, houve grande investimento, econômico e ideológico, para uma sofisticação na administração penal e carcerária.

Esse novo modelo de controle da multidão traça, portanto, um arco que vai da disciplina da carência ao governo do excesso, no qual tribunais e cárceres foram instituições fundamentais. De Giorgi (2013, p.84) parte da afirmação de um esgotamento do papel produtivo do comando capitalista para dialogar com as hipóteses foucaultianas sobre governabilidade, disciplinaridade e biopoder, definindo-os como "conceitos que representam as coordenadas essenciais daquela cartografia da modernidade e dos seus aparelhos de poder que se revelaram instrumento indispensável para compreender as diversas articulações da relação entre controle disciplinar e produção fordista". Para o autor, o centro do processo foucaultiano é a tentativa de reconstrução de uma genealogia das tecnologias de poder para decodificar a economia e as racionalidades internas dos mecanismos de controle. Os dispositivos de repressão social teriam abandonado uma lógica (controlar os desvios) para desenvolver uma função produtiva, tornados, assim, partícipes fundamentais do processo histórico de formação do capitalismo. É a transição de uma lógica de poder centrada no modelo da soberania para uma prática de poder que se nutre de uma nova "ciência de governo". Essa governabilidade compreende o conjunto constituído pelas instituições e seus procedimentos, tendo como alvo a população (biopoder) e como instrumentos técnicos essenciais os dispositivos de segurança.

Pode-se dizer que para Foucault a aquisição de poder pela burocracia foi acompanhada por uma consciência mais aguda desse poder, em um governo que se torna, por racional, menos errático e mais eficiente porque se compreende bem. Esse poder se pratica nos objetos desse governo que vão além do trabalho humano (produção) 
e da economia, mas conseguem alcançar a sexualidade e a higiene, determinando o cuidado de si. A governabilidade não é apenas o poder que proíbe, mas que regula, ordena e dispõe numa nova racionalidade.

É nesse contexto que se consolidam dispositivos e práticas de segurança cuja função é garantir o correto funcionamento do aparato de controle, de governo. As penalidades e as políticas criminais nunca deixaram, porém, de ser centrais como estratégias de controle, ou seja, aparatos de segurança. As populações que sobejam como força de trabalho e são rotuladas como problemáticas são, como sempre foram, o principal alvo dos dispositivos de repressão penal do desvio. Os "desviantes" são desde estrangeiros pobres, normalmente na condição de refugiados, até os políticos cujo sinônimo passa a ser corrupto. Esse processo da construção da definição da conduta desviante se dá por meio de uma múltipla narrativa, com práticas que lhe confirmam, estratégias e discursos que geram fobia do diferente, medo e insegurança pela incerteza, pânico com o imprevisível e ódio ao grupo identificado como desviante.

\section{ILEGALISMOS NOS JOGOS DE FORÇAS DO DIREITO}

Identificados quais foram os pressupostos do que Foucault vem a chamar de ilegalismos, passa-se a discutir mais detidamente esse conceito. Um importante intérprete de Foucault é G. Deleuze. De acordo com Deleuze, "o poder do Estado exprimir-se-ia na lei, sendo esta concebida ora como um estado de paz imposto às forças brutais, ora como o resultado de uma guerra ou de uma luta ganha pelos mais fortes” (2019, p. 36). Há aqui um pressuposto que a lei estancaria as disputas em torno do que deve ser controlado socialmente e em que sentido deve ser controlado. É como se a lei se opusesse a ilegalidade em um plano de estabilidade. Contudo, para Foucault (2006), somente uma ficção pode fazer crer que as leis são feitas para serem acatadas, bem como que a polícia e os tribunais se destinam a fazer com que 
as leis sejam respeitadas. Somente uma ficção teórica pode nos levar a acreditar que aderimos, de uma vez por todas, a lei da sociedade à qual pertencemos, sem escusas, sem pausas ou suspensões.

O Estado, a Lei e o Direito estão submetidos a uma agonística de forças sociais. Agonismo, em sentido amplo, é a noção de um universal sentido de competição, mas esse termo, conforme aponta Tuncel (2013), em Nietzsche, é informado especificamente pelo ágon presente na cultura grega arcaica. A contraposição, a contradição, a correlação de forças, a guerra é o modo como se dá o conjunto das relações que chamamos jurídicas. Cada um dos contrários somente se define, segundo Mota (2018b), na medida do agón, do pólemos. Essa é a contradição essencial do mundo: o devir, o mundo, é agón, é guerra. Por meio da noção de ágon, é possível pensar a Lei dentro de uma teoria das forças.

Diversas forças sociais, na política e na economia, influenciam os limites do que o Direito pode dizer, do que a Lei pode ser. Deleuze (2018a) explica que "a essência da força é estar em relação com outras forças [...]. A relação da força com a força chama-se "vontade"” (p. 23). Para nós, o entendimento de que a Lei está em disputa, que seu sentido está por ser determinado, que seu espaço é móvel e movediço, pode ajudar a entender não só o modo como as decisões são estabelecidas, mas também qual a hermenêutica possível de um texto em dada contingência. Assim, temos que, longe de a Lei impor um campo pacífico em que as disputas estariam superadas e de o ilegal ser, tão somente, a função de entrada para o Direito (Kelsen, 2009), entendemos, aqui, que há disputas dentro do que é estabelecido como legal e ilegal. O ilegalismo não é tão somente o que é ilegal, mas o tensionamento de forças sobre os limites do que é ilegal.

De acordo com Foucault (2006), a lei não é feita para impedir determinados tipos de comportamento, mas para diferenciar as maneiras de burlar a própria lei. A lei, assim, carrega junto de si um plano tático de ilegalismos, a despeito da consequente exclusão que cria ao estabelecer o plano da legalidade, ou seja, a ilegalidade. O Direito 
e o discurso jurídico vieram encobrir e recobrir o mapa estratégico das lutas, da guerra, mas não acabaram com estas, pois "o mapa dos ilegalismos continua a trabalhar sob o modelo da legalidade" (DELEUZE, 2019, p. 36). Enquanto guerra, o mundo é contradição e esta não há de ser dissolvida, sob pena de desfazer-se o próprio mundo. $\mathrm{Na}$ medida em que o mundo não tem fim, não tem fim a guerra. A Lei é a própria guerra e a estratégia dessa guerra em ato.

O baluarte do liberalismo, o legalismo, não realizou suas promessas, ou seja, não assegurou tratamento isonômico entre os cidadãos, pois a lei não trata da mesma maneira o quê e quem está sob seu julgo. Foucault, assim, chama a atenção para o fato de que, assim como o Estado não cessa a guerra civil na sociedade, como pressupunha Hobbes (1999), a lei não estanca as lutas e as táticas de poder. Não há, portanto, Estado apaziguado, mas guerra e tática. O Estado não tem, como explica Ewald (2000, p.42), o "privilégio da totalidade: é uma parte que se opõe às outras, que se articula com as outras”. Não há, nesse sentido, um poder acima dos demais que impõe um único modo de agir, pois mesmo dentro do Estado há guerra, e a batalha perpétua se dá em torno dos ilegalismos, nos limites do que é dito por ilegal e do legal. Gerir os ilegalismos é o lado positivo do Estado e do Direito, pois não é só limitar os direitos, mas estabelecer até onde vão os direitos. Delimitar o que é aplicável, o que é concretizável, qual interpretação é válida, qual decisão é razoável.

É importante perceber a transitividade, dentro do ilegalismo, entre o legal e o ilegal. Se há porosidade entre o formal e informal, legal e ilegal, isso não quer dizer indiferenciação entre uns e outros. Leis, codificações e regras formais, de acordo com Telles (2010, p.101), "têm efeitos de poder, circunscrevem campos de força e é em relação a elas que essa transitividade de pessoas, bens e mercadorias precisa ser situada". Não se trata de universos paralelos, sem contato entre si, muito menos de oposição entre o formal e informal, legal e ilegal. $\mathrm{Na}$ verdade, é nas suas dobras entre um e outro que se circunscrevem jogos de poder, relações de força e campos de disputa. São campos 
de força, de acordo com Azaïs, Kessler e Telles (2012, p.34), que "se redefinem e se refazem conforme a vigência de formas variadas de controle e também, ou, sobretudo, os critérios e procedimentos de incriminação dessas práticas e dessas atividades, oscilando entre a tolerância, a transgressão consentida e a repressão".

Foucault, segundo Telles (2010), desloca a discussão tautológica e estéril da binaridade legal/ilegal para colocar no centro da investigação os modos como as leis operam, não para coibir ou suprimir os ilegalismos, mas para diferenciá-los internamente. Nas dobras do legal-ilegal importa perceber seus efeitos, o modo como os jogos de poder se configuram, a distribuição diferenciada dos controles e os agenciamentos práticos que se curvam ou que escapam aos dispositivos de poder implicados nessas categorias e codificações.

O recurso ao conceito de ilegalismo, por Foucault, permitiu, segundo Lascoumes (1996), três importantes rupturas: uma conceitual, outra histórica e, por fim, uma referente à dominação social. A conceitual se deve ao fato de permitir ultrapassar categorias jurídicas penais tradicionais como infração e acusação, bem como a categoria delinquência da criminologia. Essa superação se deu ao denunciar a falsa neutralidade entre ordem e desordem como fatos históricos estáveis e universais, bem como ao atacar a falsa neutralidade das categorias criminológicas que atribuem a origem dos atos de transgressão social aos determinantes internos dos indivíduos. A ruptura histórica, por sua vez, permitiu analisar os diferentes regimes de práticas sociais que entram em jogo com as regras de direito. E, por fim, a ruptura da reflexão sobre a dominação social que repercute sobre o modo de perceber os ilegalismos da burguesia, sua ocultação intelectual como elemento de dispositivo contemporâneo de dominação.

Como explica Ewald, "os ilegalismos são o motor das transformações na tecnologia do poder" (2000, p. 44). Isso porque a delimitação do que pode ser dito pelo Direito é uma chave para controlar a batalha pelo Estado. O ilegalismo, segundo Fonseca (2012), é um jogo no interior, ao lado, da legalidade, é um jogo em torno da 
legalidade e das ilegalidades efetivamente praticadas. A tolerância do sistema legal a certas ilegalidades em determinado momento está no centro desse debate, ou seja, a mesma conduta, em certo momento, é aceita e até incentivada e, em outro, é perseguida e coibida. Segundo Fonseca, entre o que é "estabelecido pela lei e as ilegalidades que são praticadas, não se interpõe um sistema punitivo absolutamente neutro: o que ocorre é que nem toda prática ilegal deve ser punida e, no sentido inverso e ao mesmo tempo proporcional, nem toda lei deve ser respeitada" (2012, p. 132).

Isso significa, a despeito da imensa maioria da teoria do direito, que não existe, dentro de um pensamento imanente, a possibilidade de imputação lógica de uma norma. Não há, na imanência, a distinção entre essência a aparência, entre mundo real e mundo das ideias, entre inteligível e sensível, entre original e cópia (Deleuze, 2015). Assim, a aplicação de uma lógica deontológica, racional e ideal não é aplicada sem se levar em consideração as forças que a circundam. Não é, dentro do pensamento foucaultiano, possível pensar a punição como a imputação de uma norma abstrata a um caso concreto, por meio de um juízo lógico-dedutivo, puramente formal, que realizaria, diante do não cumprimento, a sanção.

No platonismo, que exerceu e exerce forte influência sobre o Direito, é como se tudo "girasse em torno de uma distinção particularmente importante, a do original e da imagem, a do modelo e da cópia. Supõe-se que o modelo goze de uma identidade superior (...) ao passo que a cópia é julgada segundo uma semelhança inferior derivada" (Deleuze, 2018, p. 167). Em uma visão platônica do Direito, portanto, deve haver uma semelhança entre original e cópia, ou seja, segundo Deleuze, um ato "não merece a qualidade (por exemplo, a qualidade de justo) senão na medida em que se funda sobre a essência (a justiça)" (2015, p. 162). A punição, no plano imanente das práticas sociais, deve, em sentido diverso ao platonismo, ser entendida como a resultante de um jogo de forças em que legalidade e ilegalidade não se opõem. A ilegalidade será determinada no plano dos ilegalismos pelas 
forças em disputa e não pelo acesso primordial a um conhecimento ontológico em um plano superior.

Para Foucault (2015), não se pode analisar uma lei sem a situar no campo real de ilegalismo em que funciona. Uma lei só se aplica dentro de um campo de ilegalismos que, de certo modo, a sustenta. Os ilegalismos correspondem, conforme explica Fonseca (2012), a uma gestão de certo número de ilegalidades. O ilegalismo rompe com a ideia de que o Estado produz as leis para serem respeitadas, não jogando luz ao fato de que, no regime geral da sociedade e do Estado, algumas leis são para serem obedecidas e outras para serem ignoradas. Os ilegalismos permitem perceber como circula a própria lei. Os jogos de força a que está submetido o Direito, determinam também o que será punido e o que será ignorado. Daí, poder se dizer, conforme Fonseca (2012), que os ilegalismos circulam entre o domínio formalizado da lei e os domínios não formalizados das práticas econômicas e sociais.

\section{CONCLUSÃO}

O presente artigo buscou expor, além da teoria dos ilegalismos, os pressupostos teóricos e históricos que a lastreiam. Assim, foram apresentadas as tensões da sociedade francesa e inglesa na consolidação da burguesia no poder, apontando o modo como as relações sociais e o controle social eram estabelecidos pelo Direito. Tal consolidação, entretanto, não faz desaparecer os demais grupos sociais e suas pretensões. Deste modo, almejou-se apresentar a maneira como os diversos grupos, nesse contexto, pressionavam o Estado na construção de um sentido para norma ante o limite do legal, estabelecendo pressões nas fronteiras do ilegal, possibilitando, assim, pensar o ilegalismo.

A compreensão de Foucault sobre os ilegalismos, portanto, desvela o quanto remanesce das heranças de um modelo de justiça pessoal e ideologicamente orientado, um modelo de justiça vigente desde a antiguidade e prevalente no mundo medieval. Mesmo que 
seja afirmado que o sistema de normas, estaticamente considerado, seja um amálgama de moral e política, porquanto seja a norma uma forma, a sugestão de que os sistemas judiciários e os jurisdicionados praticam um jogo de escolhas e acomodações dá uma nova dimensão analítica para a compreensão de inúmeros episódios culturais.

Conforme indicado como um dos objetivos do trabalho, o quadro analítico aqui apresentado permite novas leituras e pesquisas sobre as inúmeras revoltas de escravizados ao longo de todo o período em que vigeu a escravidão, desde a formação de quilombos no século XVII, até a revolta dos Malês em 1835, passando pela análise das ações de liberdade. Possibilita construir uma compreensão razoável do fenômeno de desmonte do modelo de trabalho com direitos para um modelo prevalente de trabalho sem direitos, ou precarizado. Fomenta compreender as dinâmicas populares em torno da propriedade, como a "venda da chave da casa" e a simples transmissão dos atos de posse que desafiam a formalidade cartorária do modelo legal de propriedade no Brasil. Comporta buscar uma compreensão para o tratamento jurisdicional dos desvios relativos à posse a ao porte de drogas no Brasil. Autoriza um estudo sobre as relações de ilegalidade sobre crimes financeiros e, por fim, sobre a atuação da justiça junto a normas de sentido aberto, haja vista que sobre elas há disputa sobre o limite da legalidade. São múltiplas as possibilidades de novos estudos e novas compreensões a partir do quadro analítico foucaultiano sobre os ilegalismos.

\section{REFERÊNCIAS}

AZAÏS, Christian; KESSLER, Gabriel e TELLES, Vera da Silva (Orgs.). Ilegalismos, cidade e política. Belo Horizonte, MG: Fino Traço, 2012.

DARNTON, Robert. O grande massacre de gatos: e outros episódios da história cultural francesa. Trad. Sônia Coutinho. 2. ed. São Paulo: Paz e Terra, 2015. 
DELEUZE, Gilles. Diferença e repetição. 1 ed. São Paulo: Paz e terra, 2018.

DELEUZE, Gilles. Foucault. São Paulo: Brasilense, 2019.

DELEUZE, Gilles. Lógica do sentido. São Paulo, Perspectiva, 2015.

DELEUZE, Gilles. Nietzsche. Lisboa: Edições 70, 2018 A.

DE GIORGI, Alessandro. A Miséria governada através do sistema penal. Trad. Sérgio Lamarão. Rio de Janeiro: Revan-ICC, 2006, 2. reimpr.2013. EWALD, François. Foucault, a Norma e o Direito. Lisboa, Veja, 2000.

FONSECA, Márcio Alves da. Michel Foucault e o direito. 2 ed. São Paulo: Saraiva, 2012.

FOUCAULT, Michel. À propos de l'enfermement pénitentiaire, In: Dits et écrits I. Paris: Quarto/Gallimard, 2001, p.1303-1313.

FOUCAULT, Michel. A sociedade Punitiva: curso no Collège de France (1972-1973). São Paulo: Editora WMF Martins Fontes, 2015.

FOUCAULT, Michel. Em defesa da sociedade: curso no Collège de France (1975-1976). São Paulo: Martins Fontes, 1999.

FOUCAULT, Michel. Vigiar e punir: o nascimento da prisão. Petrópolis, Vozes, 1987.

GROSSI, Paolo. História da propriedade e outros ensaios. Trad. Luiz Ernani Fritoli e Ricardo Marcelo Fonseca. Rio de Janeiro: Renovar, 2006. KELSEN, Hans. Teoria pura do Direito. 8 ed. São Paulo: Editora WMF Martins Fontes, 2009.

LASCOUMES, Pierre. "L'illégalisme, outil d'analyse». Societé \& Représentation, 1996, nov., pp. 78-84.

MOTA, Thiago. O Trágico e o Agón em Nietzsche. Revista Trágica: estudos sobre Nietzsche $-2^{\circ}$ semestre de 2008B - Vol.1 - nº 2 pp.79-92.

RUSCHE, Georg. KIRCHHEIMER, Otto. Punição e estrutura social. Trad. Gizlene Neder. 2. ed. Rio de Janeiro: Revan, 2004. Coleção Pensamento Criminológico, v.3.

SOUTO, Caio Augusto T. Direito e ilegalismos: reflexões sobre a normalização na obra de Michel Foucault. Kínesis, Vol. II, nº 04, Dezembro-2010, p. 23-39. 
TELLES, Vera da Silva. Nas dobras do legal e do ilegal: Ilegalismos e jogos de poder nas tramas da cidade. Dilemas: Revista de Estudos de Conflito e Controle Social. Vol. 2 - no 5-6 - JUL/AGO/SET-OUT/NOV/DEZ 2010 - pp. 97-126 THOMPSON, Edward Palmer. A formação da classe operária. Vol. I. Rio de Janeiro: Paz e Terra, 1987a.

THOMPSON, Edward Palmer. A formação da classe operária. Vol. III. Rio de Janeiro: Paz e Terra, 1987b.

TUNCEL, Yunus. Agon in Nietzsche. Wincousin: Marquette University Press, 2013.

\section{GRETHA LEITE MAIA}

Professora Adjunta do Departamento de Direito Processual da Faculdade de Direito da Universidade Federal do Ceará. Doutora e Mestra em Direito pela Universidade Federal do Ceará (UFC). Endereço profissional: R. Meton de Alencar, S/n - Centro, Fortaleza - CE, 60035-160, Brasil.

ORCID ID: http://orcid.org/0000-0002-6908-1772

E-MAIL: grethaleitemaia@gmail.com

\section{DAVID BARBOSA OLIVEIRA}

Doutor em Direito pela Universidade Federal de Pernambuco. Professor Adjunto da Faculdade de Economia, Administração, Atuária e Contabilidade - FEAAC da Universidade Federal do Ceará.

Endereço profissional: Av. da Universidade, 2431 - Benfica, Fortaleza - CE, 60020-180, Brasil.

ORCID ID: http://orcid.org/0000-0003-2461-2872

E-MAIL: dvdbarol@gmail.com

Recebido: 29/12/2020

Aceito: 19/09/2021 


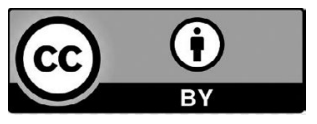

Este trabalho está licenciado sob uma licença Creative Commons Attribution 4.0 International License.

Autores e autoras cedem à Revista Sequência direitos exclusivos de primeira publicação, ficando o trabalho licenciado sob a Creative Commons Attribution 4.0 International License. A licença autoriza que terceiros remixem, adaptem e ou criem a partir do trabalho publicado, indicando o crédito ao trabalho original e sua publicação inicial. Os autores têm permissão para assumir contratos adicionais em separado, com distribuição não exclusiva da versão publicada na Revista Sequência, indicando, de todo modo, a autoria e publicação inicial neste periódico. 